\title{
Examining the Simplified Novels (SNs) as Supplementary Materials in Light of the Teachers' Objectives and Teaching Techniques
}

\author{
Mahmoud Abdelrazig Mahmoud Barakat \\ Assistant Professor, Faculty of Education, \\ University of Khartoum \& Omdurman \\ Islamic University, Khartoum, Sudan. \\ Email: barakatmahmoud99@yahoo.com
}

\author{
Amna Mohammed Bedri \\ Associate Professor, Ahfad Institute of \\ Languages, Ahfad University for Women, \\ Khartoum, Sudan. \\ Email: amnambedri@ hotmail.com
}

Received: 7 February 2018. Revised: 20 March 2018. Accepted: 10 April 2018

\begin{abstract}
Simplified novels are believed to assist in the achievement of a number of language and non-language objectives. This paper will examine the possibility of using the simplified novels as supplementary materials with secondary school students from the teachers' perspectives. The study uses the interview as a tool to elicit data about the teachers' objectives and the techniques employed in teaching the simplified novels. Ten teachers are included in the sample: 4 females and 6 males. They all work in model secondary schools and teach the simplified novels to their students. It has been found that the main objective is to improve the students' reading skills with a moderate potential for supporting their oral/aural skills. Increasing students' motivation is viewed as an important objective, while non-language objectives have received no attention. As for the teaching techniques, loud reading is found to be dominant, with almost complete absence of silent and home reading. Discussion comes in the second place (5 teachers), while role play is used by only 3 teachers. The study recommends the use of more challenging materials as the teachers believe the simplified novels being used do not help increase their students' vocabulary. Moreover, the teachers' beliefs about loud reading and non-language objectives need reexamination.
\end{abstract}

Keywords: simplified novels, objectives, techniques.

How to Cite: Barakat, M.A.M., \& Bedri, A.M. (2018). Examining the simplified novels (sns) as supplementary materials in light of the teachers' objectives and teaching techniques. Language Circle: Journal of Language and Literature, 12(2), 115-122.

\section{Introduction}

Since 2008 the Sudan Ministry of Education has introduced the MacMillan simplified novels $\mathrm{SNs}$ as supplementary materials to the main language textbook in the secondary schools to help improve the students' reading, vocabulary and overall English language skills. This paper aims to examine the SNs in light of the teachers' objectives and the techniques they use in teaching them.
Length can make using the original novel in the classroom a time-consuming task. This problem in the limited classroom time can partially be solved by using simplified versions. Brownlie et al. (2006, p. 71) suggest that not every chapter need be processed in the same depth and not every literary technique or comprehension strategy needs to be covered, i.e., teachers have to be selective in their focus and clear about the acceptable 
degree of objective achievement. Tsai (2012, p. 103) advocates the use of novel as a main reading material in the foreign language classroom. He investigated the students' perceptions and found positive results in support of exploiting the novel despite the difficulties they had faced. Novels and good stories, according to (Harris et al. 2011, p. 65), serve a number of functions such as developing learners' awareness of narrative discourse structure, stimulating interest and imagination and raising cultural awareness. Cremin (2009, p. 113) believes the teacher's role should be to seek out fiction texts which require the children to actively participate in making meaning and they should use a wide range of open-ended strategies that foster children's curiosity and develop their personal responses in spoken and written language. Zoreda et al. (2008, p 28) suggest using simplified novels SNs with their film adaptations to achieve linguistic and intercultural goals in EFL classroom.

Original literary works, according to Littlewood (2000, p. 178 and p. 182), can help foreign language learners from different perspectives: language, style, subject matter (content), symbolization and intellect. These perspectives which can be viewed as objectives or goals are necessarily positioned in a hierarchy. The more advanced the learners' language level is, the more likely their objectives would go beyond language itself. Most interestingly, Littlewood (ibid) states that much of what is said about literary works as regards these perspectives at advanced stages "can also be applied to constructed texts used at earlier levels." Vincent (2000, p. 214) states that "one advantage of the reduction in length and complexity of a simplified version of a standard text is that it provides an opportunity for literary-like behavior ... and an introduction to making judgments of value." Picken (2007, p.151) analyzed some SNs and he believed they could help build the learners' metaphorical abilities and "give readers the kind of interpretative and value-related experience that is called literary."

According to Oxford's Guide to the 'Why' and 'How' of Using Graded Readers (2013, pp. 6-7), reading many SNs in an extensive reading program develops reading skills and strategies. These readers should be at or below the learners' reading ability so as to develop reading fluency and confidence as well as gradually build vocabulary. In addition to improving reading fluency and vocabulary, MacMillan's Guide to Graded Readers (2006, pp. 7-8) adds the following advantages: improving language construction (grammar and discourse), improving writing skills, building confidence and independent learning and creating a positive attitude.

\section{Methodology}

The study has used the interview to generate accounts of 10 teachers from model schools. The sample includes 4 females and 6 males, which is deemed sufficient to represent both genders. The sample represents 8 schools from three areas in Khartoum State. All the teachers in the sample are experienced. Their experiences range between 15 and 26 years of continuous career in teaching English in the secondary schools. They are all graduates of English and two of them hold MAs in applied linguistics (ELT). It is also worth noting that using tape-recording was avoided in order to encourage the teachers to talk freely without feeling any threats of being vulnerable.

No claims of generalized results are made unless further quantitative evidence is found to support them. Individual cases and 
multi-layered meaning are what these interviews attempting to allow for.

\section{Findings And Discussion The Objectives}

Table 1 shows the teachers' views about the possible objectives that can be achieved by using the SNs in the classroom with secondary school students. Seven out of the ten teachers of the sample believe the SNs can help improve the students' reading skills. The other three are skeptical of the quality of the language which they describe as extremely simplified and may not allow for adequate training in all the sub-skills of reading. In order for the enhancement of the reading skills to be realized, it is not only important to carefully select the reading materials, but also to consider the students' language level and the teaching techniques employed by the teachers. Generally speaking, it can be stated that the SNs can be used to supplement the reading passages of the language textbook and improve the students' reading skill

Table 1 The Teachers' Objectives

\begin{tabular}{lccccccccccc}
\hline Objectives & T1 & T2 & T3 & T4 & T5 & T6 & T7 & T8 & T9 & T10 & No \\
\hline Reading & $\checkmark$ & $\checkmark$ & $\checkmark$ & $\checkmark$ & $\checkmark$ & $\times$ & $\checkmark$ & $\times$ & $\checkmark$ & $\times$ & 7 \\
Oral/aural & $\checkmark$ & $\checkmark$ & $\checkmark$ & $\checkmark$ & $\times$ & $\times$ & $\checkmark$ & $\times$ & $\times$ & $\checkmark$ & 6 \\
skills & & & & & & & & & & & \\
Writing & $\times$ & $\times$ & $\times$ & $\times$ & $\times$ & $\times$ & $\times$ & $\checkmark$ & $\times$ & $\times$ & 1 \\
Overall & $\checkmark$ & $\times$ & $\times$ & $\times$ & $\times$ & $\times$ & $\times$ & $\times$ & $\times$ & $\times$ & 1 \\
education & & & & & & & & & & & \\
Motivation & $\times$ & $\checkmark$ & $\times$ & $\checkmark$ & $\checkmark$ & $\times$ & $\times$ & $\checkmark$ & $\checkmark$ & $\checkmark$ & 6 \\
Vocabulary & $\times$ & $\times$ & $\times$ & $\times$ & $\times$ & $\times$ & $\checkmark$ & $\checkmark$ & $\times$ & $\checkmark$ & 3 \\
Gain marks & $\times$ & $\times$ & $\times$ & $\times$ & $\times$ & $\checkmark$ & $\checkmark$ & $\times$ & $\times$ & $\times$ & 2 \\
appreciation & $\times$ & $\times$ & $\times$ & $\times$ & $\times$ & $\times$ & $\times$ & $\times$ & $\times$ & $\times$ & 0 \\
Cultural & $\times$ & $\times$ & $\times$ & $\checkmark$ & $\checkmark$ & $\times$ & $\times$ & $\times$ & $\checkmark$ & $\times$ & 3 \\
enrichment & & & & & & & & & & & \\
Critical & $\checkmark$ & $\times$ & $\times$ & $\times$ & $\times$ & $\times$ & $\times$ & $\times$ & $\times$ & $\times$ & 1 \\
ability & & & & & & & & & & & \\
\hline
\end{tabular}

Six out of the ten teachers think the SNs can provide opportunities for oral/aural practice in the classroom. The themes, events and characters of the SNs can form the basis for discussions in which the students can express their opinions freely. The teachers should therefore be aware of the need to allot time for activities that generate oral response. Such activities should be varied and go beyond the simple question-and-answer technique to sustain students' interest and engagement. However, four teachers of the sample do not see a possibility for addressing this objective by means of using the SNs, which indicates lack of integration of the oral/aural skills and the reading skill. A reading lesson need not always be done with the students' heads down to trace prints. Reading is a kind of intentional mediation between the text's and one's own store of linguistic elements and experiences. This process can benefit from discussion which supports understanding of the written text and 
helps incubate extra ideas for further oral response.

It is noticed that only one teacher believes in relating the SNs to the writing skill. The gap between the SNs and the improvement of the writing skill is even wider than the gap between them and the development of the oral/aural skills. This means that there is still a strong belief that the amount of writing practice prescribed in the main language textbook is sufficient and does not need supplementation by the SNs. Accordingly, it can be deduced that the main objective of using the $\mathrm{SN}$ is to help the students' reading skills, with a moderate potential to support their oral/aural abilities.

Vocabulary development is generally an important objective in language learning and teaching. However, only three teachers believe that the SNs used in the secondary schools assist in the achievement of this objective. The majority of the sample $\_7$ teachers_do not see the SNs as helpful in this area. It can be stated that the chosen grades of the SNs contain vocabulary items that are far below the students' actual knowledge of vocabulary, and could hardly add new words to them. These materials may be suitable to address this objective if the students can read large amounts of them as extensive reading practice. The potential of developing their vocabulary increases with the amount of reading available to them. Yet, only a limited number of these SNs is possible to bring into the classroom for formal study. Hence, there is a pressing need to include some more advanced SNs to fill this gap and enlarge the students' vocabulary.

Most interestingly, it is believed, the SNs can play an important role in motivating the students to read. The story-line type of material is more appealing than the ordinary materials usually found in the textbook. If motivation is enhanced, many students' reading habits will be influenced positively as well as their overall language. Therefore, increasing students' motivation should be considered an objective in its own right because it can push them toward autonomy by looking for other intriguing materials to read for pleasure. However, four of the teachers do not consider the SNs as motivating elements in the teaching-learning process. This may be taken as a negative statement against the content and themes of some of the materials which need rethinking and substitution. Investigating students' interests and views can assist in the evaluation and selection of the books. Nevertheless, it is often hard to guarantee consensus about matters of tastes and dispositions.

Only three teachers believe the SNs can achieve cultural enrichment. This could indicate that the cultural components are either insufficient or they just yield a secondary byproduct that should not be considered as a main objective. Relevant to this point is the overall education of the students, which is considered by only one teacher of the sample. Cultural enrichment and education of the whole person gain less attention from the teachers who view the pure language objectives as their main concern. This attitude needs to be analyzed, understood and considered in teacher training. Language never exists in vacuum and could hardly be envisaged in an abstract state unless in the minds of theoretical linguists and philosophers. As a system of communication, language mixes with ideas, culture and every aspect of life. Thus, non-language and general educational objectives are part of the language teachers' agenda of objectives. 
Critical abilities and language appreciation almost have no place in the teachers' objectives. Although the $\mathrm{SNs}$ are literary-like materials, they cannot help achieve these two objectives. The literary elements in the SNs are limited and do not allow for full development of the literary faculties. Nevertheless, they can guide the students a step further toward appreciation of style if the objective is set and the appropriate material is chosen. Critical abilities need not be of the technical type exercised by specialists. If the students can launch judgments about the characters, their words, utterances and actions, with reference to certain parts of the SNs, their general reasoning and thinking abilities can be enhanced. The SNs can be exploited to the utmost and the language objectives consolidated if these two objectives are taken into consideration.

It might seem strange to regard increasing students' marks in the English language as a target to be achieved through the teaching of the SNs. This situation has been created by the fact that there is an optional section in the Sudan School Certificate Examination of English which requires the students to answer some questions related to the SNs instead of another language section given the quarter of the total mark of the subject (25 marks). The other language section includes some subjective items (letter writing and summary), while the SNs section includes objective items (MCQs, true-or-false questions and a 5-items matching question). There is a common belief among teachers and students that answering the questions of the SNs guarantees gaining marks, as compared to the language section which the students try to avoid. Actually, this finding can neither be reinforced nor refuted from the limited sample included in this small-scale study. The nature of this study permits understanding individual cases rather than launching generalized results. Only three teachers of the ten included in this sample believe that the SNs can help in scaffolding students' achievement in the examinations. It can be said that gaining marks is a rather superficial issue which has been created by an external factor - the examination - and does not relate fundamentally to the SNs.

\section{The Techniques}

It is beneficial to investigate some of the common techniques used in teaching the SNs and relate them to the objectives stated by the teachers. Table 2 displays five of them: silent reading, loud reading, home reading, discussion and role play.

Table 2 The Techniques

\begin{tabular}{lccccccccccc}
\hline Techniques & T1 & T2 & T3 & T4 & T5 & T6 & T7 & T8 & T9 & T10 & No \\
\hline $\begin{array}{l}\text { Silent } \\
\text { reading }\end{array}$ & $\checkmark$ & $\times$ & $\times$ & $\times$ & $\times$ & $\times$ & $\times$ & $\times$ & $\times$ & $\times$ & 1 \\
Loud reading & $\checkmark$ & $\checkmark$ & $\checkmark$ & $\checkmark$ & $\checkmark$ & $\checkmark$ & $\checkmark$ & $\checkmark$ & $\checkmark$ & $\checkmark$ & 10 \\
$\begin{array}{l}\text { Home } \\
\text { reading }\end{array}$ & $\checkmark$ & $\times$ & $\times$ & $\times$ & $\times$ & $\times$ & $\times$ & $\times$ & $\times$ & $\times$ & 1 \\
Discussion & $\checkmark$ & $\checkmark$ & $\checkmark$ & $\checkmark$ & $\times$ & $\times$ & $\checkmark$ & $\times$ & $\times$ & $\times$ & 5 \\
Role play & $\checkmark$ & $\times$ & $\checkmark$ & $\times$ & $\times$ & $\times$ & $\times$ & $\times$ & $\times$ & $\checkmark$ & 3 \\
\hline
\end{tabular}


Although the main objective of using the $\mathrm{SNs}$ is to improve the reading skills, the dominant technique is found to be the loud reading. There is a consensus among the teachers of the sample that loud reading is their practical choice. This practice is part of a prevalent culture that can be traced to the beginnings of the traditional educational systems in the society. It also relates to the roles assigned to the teacher and student, the former being active and the latter recipient. In contrast, using the silent reading technique gains the approval of only one teacher; the majority of them refrain from using it in teaching the SNs. There is a complaint that the students cannot be trusted in silent reading as at least some of them will not read. At the same time forcible follow-up activities, which might succeed with some students, can generate reluctance and undesirable attitudes that jeopardize the whole process of language learning. Comprehension is affected when the students feel threatened or targeted. Another problem is that the teachers feel losing control of the process which they consider as the core of their responsibilities: guiding their students' learning. Unfortunately, this issue is entwined with a number of complicated psychological factors that need high consideration in teacher education. Cultivating the habit of silent reading into the students is a major concern that necessitates working with both parties_ the teachers as well as the students. Home reading like silent reading is also absent since it takes place out of the school province. In order to achieve the objective of helping the students to read adequately, the teachers' techniques and strategies need to be revisited. The SNs can be very useful in reworking this thorny issue.

Discussion and role play target the oral/aural skills. Half of the sample use discussion to teach the SNs in the classroom. They integrate reading with listening and speaking. On the other hand, discussions are frequent in the language textbook and may consume a considerable proportion of the classroom time. Therefore, the teachers who do not use this technique in teaching the SNs try to save time for other classroom activities. Nonetheless, the quality of discussion with teaching the SNs can vary and make the class period interesting. Role play is a familiar technique that is encountered in the textbook. The teacher may also use it and assign different roles emerging from the SNs to their students. They can play the roles of the characters according to specific situations and parts of the SNs. Only three teachers use this technique and underscore its value in supporting their students' oral/aural skills.

\section{Conclusion}

To sum up, it can be claimed that the quality of the SNs does not help achieve the hoped objectives. First, the language content is poor and the amount of vocabulary is limited. Second, much of what the SNs are expected to address is already covered in the language textbook. The writing activities and discussions in the students' textbook are thought to be enough which is why the teachers do not attempt to exploit the SNs in this area. However, the teachers' adherence to loud reading and disregard of silent reading play their role in this failure. It is necessary to reexamine loud reading and address this problem in teacher training programs. The SNs contribute to motivating students which is important in language teaching and learning. Non-language objectives are absent and could hardly be related to the SNs. This is because the cultural elements in them are 
Barakat, M.A.M., \& Bedri, A.M. (2018). Examining the simplified novels (sns) as supplementary materials in light of the teachers' objectives and teaching techniques. Language Circle: Journal of Language and Literature, 12(2), $115-122$.

limited and the teachers' attention to them is secondary.

\section{References}

Brownlie, F., Feniak, C., \& Schnellert, L. (2006). Student diversity: Classroom strategies to meet the learning needs of all students. Available at https://www.goodreads.com.

Cremin, T. (2009). Teaching English Creatively. 1st ed. Available at www.ebookstore. tandf.co.uk.

Harris, J., \& Duibhir, P. O. (2011). Effective language teaching: A synthesis of research. NCCA Research Report No 13. Dublin. Available at www.ncca.ie.com

Littlewood, W. T. (2000). Literature in the School Foreign-Language Course. In Brumfit, C. J. \& Carter, R. A. (eds.), Literature and Language Teaching. Applied Linguistics Series: OUP.

MacMillan (2006). Using Graded Readers in the Classroom. MacMillan Readers. Available at www.macmillanenglish.com/.

Oxford Graded Readers (2013). The 'Why' and 'How' of Using Graded Readers. Rob Waring: OUP. Available at www.oupjapan.co.jp.,viewed.

Picken, J. D. (2007). Literature, Metaphor and the Foreign Language Learner: Palgrave. Macmillan.

Tsai, C. (2012). Students' perceptions of using a novel as main material in the EFL reading course. English Language Teaching, 5(8), 103-112. Retrieved from http://dxc.doi.Org/ $10.5539 /$ elt .

Vincent, M. (2000). simple text and reading text part 1: Some general issues. In Brumfit, C. J., \& Carter, R. A. (eds.). Literature and Language Teaching: OUP.

Zoreda, M. L., \& Vivaldo-Lima, J. (2008). Scaffolding linguistic and intercultural goals in EFL with simplified novels and their film adaptations. English Teaching Forum, 3(November), 22-29. 